\title{
Nestling barn owls beg more intensely in the presence of their mother than in the presence of their father
}

\author{
ALEXANDRE ROULIN* \& LOUIS-FELIX BERSIER† \\ ${ }^{*}$ Department of Ecology and Evolution, University of Lausanne \\ $\dagger$ Department of Biology, University of Fribourg
}

\begin{abstract}
Nestling begging behaviour may be an honest signal of need used by parents to adjust optimally both feeding rate and within-brood food allocation. Although several studies showed that mothers and fathers can be differentially responsive to nestling begging behaviour with one parent showing a stronger tendency to feed the offspring that beg the most, little information is yet available on whether offspring beg for food at different intensities from the mother than father. In the present study, we investigated in nestling barn owls whether the intensity of vocal begging behaviour in the presence of the mother and in the presence of the father is different. A difference is expected because reproductive tasks are divided between the sexes with fathers bringing more food items to the nest than mothers. The results show that although mothers transfer their prey item to one of the offspring more rapidly than fathers once in their nestbox, nestlings begged more intensely in the presence of their mother than in the presence of their father. To our knowledge, this is the first empirical evidence that offspring vocalize to different levels in the presence of their mother than in the presence of their father.
\end{abstract}

Keywords: barn owl; begging; parent-offspring conflict; parental care; sexual conflict; sibling negotiation; Tyto alba

Theory proposes that family members are in conflict over parental investment with offspring requesting more resources than parents are willing to concede (Trivers 1974; Godfray 1995). Parents are reluctant to provide all the food requested by their offspring because this behaviour would jeopardize parental investment in future breeding attempts (Trivers 1974; Stamps et al. 1978; Parker \& Macnair 1979; Parker 1985). Offspring solicit more resources than would be optimal to the parents because an increase in their condition as a result of extra parental investment would outweigh the loss of quality and/or quantity of future siblings in terms of inclusive fitness. For this reason, each nestling is selected to solicit a larger than equal share of the resources (Parker \& Macnair 1979; Mock \& Parker 1997) by vocalizing and jostling for the position where parents predictably bring food items (McRae et al. 1993; Mock

Correspondence: A. Roulin, Department of Ecology and Evolution, Biophore, University of Lausanne, 1024 Lausanne, Switzerland (email: alexandre.roulin@unil.ch).Louis-Félix Bersier is at the Department of Biology, Ecology and Evolution Unit, University of Fribourg, 1700 Fribourg, Switzerland.
\& Parker 1997). Honest signalling models provide a resolution of these family conflicts by proposing that begging signals are costly to produce. In this way, only needy nestlings are willing to beg vigorously giving an opportunity to parents to reliably assess offspring need because misrepresentation of need is selected against (reviewed in Johnstone \& Godfray 2002). Experimental studies demonstrated that mainly needy nestlings are willing to beg vigorously (e.g. Mondloch 1995), and that parents feed preferentially needy offspring (e.g. Leonard \& Horn 2001) and increase feeding rate when offspring beg more conspicuously (e.g. Ottosson et al. 1997; Burford et al. 1998).

In several taxonomic groups of birds including raptors and owls, sex-roles in reproduction are well defined for instance with males providing most food items and females taking care of the offspring in the nest (Newton 1979; Mikkola 1983). In such a situation, females and males may not be similarly sensitive to offspring begging. At least in passerines, females often feed preferentially late-hatched and thereby needier offspring, and hence females may be more sensitive than males to begging in their decision to which offspring to feed first (Slagsvold 
1997; Lessells 2002; unfortunately this aspect has not yet been investigated in raptors and owls). In contrast, because males provide most food items to their brood, they may assess the overall offspring begging level to adjust feeding rate, and hence males may be more sensitive than females to offspring begging. Alternatively, because males are already feeding their brood at a high rate, only females may be able to further increase feeding rate in case offspring beg more intensely (e.g. Tolonen \& Korpimäki 1996). In this case, females would be more sensitive than males to offspring begging to adjust feeding rate. These examples show that it is difficult to propose a priori predictions regarding which of males and females are more sensitive to begging, and in turn whether offspring should beg more conspicuously towards their mother or father.

When the fitness benefits derived per unit of begging effort directed to the mother and father are not the same, nestlings may beg differentially from one of the two parents. For example, if mothers are more likely than fathers to feed the offspring that beg most intensely, offspring should beg more vigorously towards their mother than towards their father. A study in the great tit, Parus major, showed that experimentally food-deprived nestlings indeed compete more intensely for the withinnest location where the mother rather than the father usually feeds the nestlings (mother's and father's feeding locations are not the same; Kölliker et al. 1998). To our knowledge, this is the unique published study reporting that nestlings behave differently in the presence of their mother than in the presence of their father. However, to date there is still no empirical study testing whether offspring produce more begging vocalizations towards their mother or their father. This may frequently be the case because in several species mothers and fathers respond differentially to begging (Kölliker et al. 1998; Krebs 2001; Quillfeldt et al. 2004; but see Price 1998; Whittingham et al. 2003).

Here we investigated whether in the barn owl nestlings beg for food differentially from their mother than from their father. Before offspring are two-week-old, the male hunts most food items and transfers them to the mother who distributes them among the offspring; later the male provides about two-thirds of the prey items and delivers them himself to one of the offspring. Because father and mother can be easily recognized once at the nest (they differ in size and behaviour), we predict that nestlings beg differently in the presence of the mother than in the presence of the father (to which parent nestlings should beg at the highest level is difficult to predict). To examine whether this behaviour depends on offspring need, as shown in the great tit where nestlings compete more intensely to be fed by their mother than by their father only when food-deprived (Kölliker et al. 1998), we measured begging levels in experimentally food-deprived and food-satiated broods. To better understand why nestlings may beg more vigorously towards one of the two parents, we recorded the total amount of time spent by parents at the nest and the amount of time taken by mother and father to transfer a food item to one of the offspring once at the nest. A parent that takes less time may be less sensitive to begging in its decision to which offspring to feed first or, alternatively, it may be highly sensitive to begging and rapidly assess which chick to feed first. We also recorded nestling vocalization in the absence of parents (so-called sibling negotiation), a behaviour that is highly sensitive to food need with nestlings vocalizing more intensely when more hungry (Roulin et al. 2000). Therefore, vocalization behaviour in the absence of parents should indicate whether brood food need differs before the arrival of the mother and father.

\section{METHODS}

\section{Study Organism}

Although being nocturnal on the European continent, barn owl parents store food in their nest allowing offspring to spread consumption of meals over $24 \mathrm{~h}$ (Roulin 2004a). This bird is medium-sized with breeding males weighing on average $315 \mathrm{~g}$ and breeding females weighing $333 \mathrm{~g}$ (Baudvin 1986). This size dimorphism implies that males are less noisy than females when entering their nest cavity (in our study area owls land on a perch installed just beside nestboxes) potentially implying that offspring can recognize which parent is feeding them. Males frequently produce specific calls when they are very close to the nest, perhaps to indicate their identity. In the nest, females often produce another type of call apparently to induce sibling competition (personal observation). A barn owl brood contains between one and nine nestlings, and nestlings take their first flight around 55 days of age. Nestling age can be estimated by measuring the length of the flattened wing from the bird's wrist to the tip of the longest primary (Roulin 2004a). Before offspring are two weeks of age, the father gives food item to his partner who distributes them to the offspring, and afterwards the mother delivers one third of the prey items to the offspring and each parent gives itself its prey item to one of the offspring (Roulin 2002; Durant et al. 2004). Mothers and fathers deliver similar-sized prey items (Durant et al. 2004). Male and female nestlings vocalize in the absence and presence of parents to similar levels, and juniors vocalize in the absence and presence of parents to higher levels than their senior siblings mainly because they are more hungry rather than because they are smaller (Roulin 2004b). Based on the same experimental data set as the one used in the present paper, we have already shown that in the absence of parents nestlings vocalize more intensely when food-deprived compared with when food-satiated; in the presence of parents, nestling begging rate is not associated with offspring need (Roulin et al. 2000; Roulin 2001). In the presence of parents all nestlings vocalize (Bühler \& Epple 1980; personal observation).

\section{Begging in the Presence of Mother and in the Presence of Father}

The study was performed in a population of barn owls located in western Switzerland, from June to August 1997. 
We used 27 broods containing on average 4 (range 2-7) nestlings aged 36 (range 18-49) days. Brood size was not correlated with mean nestling age (Pearson correlation: $r=0.009, N=27, P=0.96)$. At 18 days of age, nestlings are thermo-independent implying that parents come to the nest only to feed them; during daylight hours they sleep outside the nestbox, often in another barn. Because in the barn owl food consumption during the day is a natural process, and because nestlings spread meals during the whole day and night (Roulin 2004a), we could manipulate offspring need without disturbing the families by offering two laboratory mice per nestling in the morning at 0900 hours. During the whole day, each nestling consumed on average 1.7 mice ( $34 \mathrm{~g}$ ), and hence in the evening they were 'food-satiated'. To food-deprive nestlings, we removed any prey remains, that is, 1.0 prey item $(=31 \mathrm{~g})$ per chick in the case where we food-satiated nestlings the day before, and 0.2 prey remains per chick (= $7 \mathrm{~g}$ ) otherwise. Removal of prey remains at 0900 hours ensured that nestlings could not eat during the whole day, and hence in the evening they were 'food-deprived'. The two treatments 'food-satiated' and 'food-deprived' were applied to all 27 broods in two successive days, and their order was randomized across nests. As shown in Roulin (2001), this experiment successfully altered nestling hunger and behaviour. To show that our manipulations affected similarly senior and junior nestlings (defined with hatching date), we weighed nestlings at 0900 hours and $12 \mathrm{~h}$ later (i.e. 2100 hours). Mixed model ANOVA with nest site as a random factor and hatching rank (senior versus junior) as a factor showed that body mass change during $12 \mathrm{~h}$ was not associated with hatching rank both when nestlings were food-deprived and when they were food-satiated $(P>0.87)$.

One day before manipulating food supply, we placed a microphone inside nestboxes to record nestling calling behaviour and we installed an infrared-sensitive video camera outside ( $N=22$ nests) nestboxes to record the amount of time parents spent on the perch. This information is important because if, for instance, mothers stay longer on the perch than their male partner, nestlings may become too tired to beg before their mother enters the nestbox. For this reason, nestlings may beg less intensely in the presence of their mother than in the presence of their father. In five cases, we had to install the video camera inside the nestbox. Males were previously ringed on the right leg and females on the left leg to recognize them on video footage and to measure feeding rates defined as number of prey items delivered at the nest between 2130 hours and 0530 hours. Arrival time at the nest is the time when parents arrived on the perch with a prey item (2130 hours is time ' 0 ' and 0530 hours time ' 8 ').

For each nest, and both when nestlings were experimentally 'food-satiated' and 'food-deprived', we recorded nestling and parental behaviour during $8 \mathrm{~h}$ between 2130 hours and 0530 hours. Playing back the films, we counted the calls produced by all offspring in the absence of parents during 30-s samples every $15 \mathrm{~min}$. Calls were therefore counted blind with respect to which parent came next. For each feeding visit, we considered number of calls counted not longer than 15 min before arrival of the parent. This number of calls was divided by number of nestlings, a measure referred to as 'sibling negotiation' after Roulin et al. (2000).

For each parental feeding visit, we measured the amount of time parents spent at the nest (i.e. the time between when an adult enters and goes out of its nestbox), and during this time period we counted calls produced by all offspring. Because in most cases the video camera was placed outside nestboxes, we could not determine the exact time when parents gave their prey item to one of the chick. Number of calls was divided by number of nestlings, a value denoted as 'begging'. We did not consider calls produced when parents were on the perch. We restricted the analyses to those visits when parents brought one prey item (520 out of 608 visits, $85.5 \%$ ), and we did not consider 72 cases where parents fed their offspring instantaneously from the perch without entering the nestbox. We discarded from our data set two parental feeding visits because the mother stayed an unusually long period of time in her nestbox (more than $8 \mathrm{~min}$ ). Because only one parent was at the nest at a time and because males delivered prey items to their brood themselves (they did not give items to their partner), we were able to record begging behaviour in the presence of the father and mother separately. On the video footage, we could identify to the species level most prey items brought by the parents (Table 1 ).

\section{Sequence of Mother-Father Feeding Visits}

If mothers and fathers feed their brood in different parts of the night or if they show predictable patterns of arrivals, offspring may be able to predict which parent will arrive next. To test this hypothesis, for each nest and treatment, we analysed if the sequence of malefemale arrivals differed from random expectation with a

Table 1. Mean number of prey items brought by male and female parents in 27 nests during two nights

\begin{tabular}{|c|c|c|c|c|}
\hline \multirow[b]{2}{*}{ Prey species } & \multicolumn{2}{|c|}{ Father } & \multicolumn{2}{|c|}{ Mother } \\
\hline & Number & $\%$ & Number & $\%$ \\
\hline $\begin{array}{l}\text { Common vole (Microtus } \\
\text { arvalis) }\end{array}$ & 8.8 & 67.48 & 4.0 & 63.69 \\
\hline $\begin{array}{l}\text { Wood mice (Apodemus } \\
\text { spp.) }\end{array}$ & 1.6 & 12.27 & 0.6 & 9.55 \\
\hline $\begin{array}{l}\text { Water vole (Arvicola } \\
\text { terrestris) }\end{array}$ & 0.8 & 6.14 & 0.3 & 4.78 \\
\hline M. arvalis or $A$. terrestris & 0.5 & 3.83 & 0.3 & 4.78 \\
\hline Shrews spp. & 0.2 & 1.53 & 0.04 & 0.64 \\
\hline $\begin{array}{l}\text { Dormouse (Muscardinus } \\
\text { arvellanarius) }\end{array}$ & 0 & 0 & 0.04 & 0.64 \\
\hline $\begin{array}{l}\text { Unidentified small } \\
\text { mammals }\end{array}$ & 1.1 & 8.44 & 1.0 & 15.92 \\
\hline Skylark (Alauda arvensis) & 0.04 & 0.31 & 0 & 0 \\
\hline Sum & 13.0 & 100 & 6.3 & 100 \\
\hline
\end{tabular}

For example, across 27 nests each father brought on average 8.8 common voles per night. 
two-tailed runs test for dichotomized data (Sokal \& Rolff 1995). Runs tests are used to evaluate whether events occur in a random sequence. In our case, events fall into two categories: female visit (F) and male visit (M). Two alternative scenarios are therefore possible. First, all events of a category tend to occur first (e.g. MMMFFF), and second, events tend to be alternative (e.g. MFMFMF). The test was applied to each brood and treatment separately. We evaluated the overall significance of the results with Fisher's formula for combining probabilities (Sokal \& Rolff 1995). To avoid low power of the test, only nights with nine or more feeding events were used in this analysis. Over the 54 experimental nights, 30 yielded enough feeding events to provide reliable runs tests, a significant runs test indicating that sequence of parental arrivals is not random.

\section{Rapidity with which Food is Transferred from Parents to Offspring}

To investigate whether mother and father differ in the rapidity with which they transfer food to their offspring once in their nestbox, we created 65 two-chick broods in 1997, 1998, 2000 and 2001. We used exclusively twochick broods because in larger broods it is difficult to record behaviour of each single individual. In the evening at 2130 hours, two siblings were randomly chosen per nest and their nestmates were temporarily put in a large plastic pail (diameter $=0.6 \mathrm{~m}$; height $=0.8 \mathrm{~m}$ ) at some distance from the nest until midnight when they were brought back in their nest. Mean age of the nestlings was 36 days (range 21-53 days). An infrared-sensitive camera and a microphone were installed in nestboxes without any apparent signs of distress to either the adults or nestlings. Once a parent entered its nestbox at the first feeding visit of the night, we measured the amount of time this parent took to transfer its prey item to one of the two offspring. Parents were captured at least one week before filming, and males and females ringed on a different leg to recognize their identity on the videos. Because parents were not always visible on the videotapes, we could record data in 26 breeding males and 11 breeding females.

\section{Statistical Procedure}

All statistical analyses were performed with the package JMP IN 5.1 (SAS Institute Inc., Cary, NC, U.S.A.), except runs tests which were done with SPSS release 12.0 (SPSS Corp., Chicago, IL). In mixed model ANCOVAs, we entered nest site as a random categorical variable using the REML option. To normalize distributions, we logtransformed negotiation and begging values and time spent by parents on the perch and at the nest. We examined the relationship between begging rate and sex of parents by entering the amount of time parents stayed at the nest as a covariate because our aim is to compare begging in the presence of mother and in the presence of father that stayed the same amount of time at their nest. We did not calculate begging rate as number of begging calls per second because comparison of begging rate in the presence of parents that stayed a different amount of time at the nest may provide spurious results. Indeed, begging rate is likely to decline with time implying that begging rate measured during different periods of time cannot be compared in this way. $P$ values less than 0.05 were considered significant. Means are quoted \pm SE.

\section{Ethical Note}

Manipulation of food supply was carried out during daylight hours, a time when chicks can sometimes eat food stored at night by the parents. In a long-term study of a barn owl population, prey remains were found during the day in $80 \%$ of the nests at hatching and this proportion progressively decreased to $10 \%$ at fledging; in nests with prey remains at 1000 hours, each chick consumed on average 0.5 items before 2045 hours (Roulin 2004a). This means that the experiment where we kept chicks without food during daylight hours had probably no dramatic effect on long-term survival and condition. Because each chick that was food-deprived on one day was also food-supplemented on another day (at that occasion each chick consumed $34 \mathrm{~g}$ of laboratory mice; daily food requirement is $63 \mathrm{~g}$ at 20 days of age, $80 \mathrm{~g}$ at 31 days followed by a decrease to $60 \mathrm{~g}$ at 60 days; Durant \& Handrich 1998), the potential negative effect of the food-deprival experiment should have been compensated. Laboratory mice came from a rehabilitation station where injured raptors are treated. This station obtained mice from big manufactures who eliminate animals unsuited to research. On video footage, there was no sign that our manipulations disturbed broods.

In the experiment for which we created two-chick broods without manipulating food supply, no detectable negative effect on reproductive success could be detected. All 65 experimental nests produced fledglings. Furthermore, in 48 nests where we could determine whether brood size at the time of experimental tests and fledging differed (many experiments were performed at fledging precluding any analysis), only 8 out of 230 (3\%) nestlings died suggesting that losses were because of natural causes. Also, experiments did not appear to impair nestling quality, because mean fledging body mass was $348 \mathrm{~g}$, a value that is even greater than the one determined in another study performed in the same population (325 g; Roulin 1998). When we temporarily removed chicks from their nests, we kept them in a large plastic pail (diameter $=0.6 \mathrm{~m}$; height $=0.8 \mathrm{~m}$ ) with many large holes to allow an appropriate air exchange.

\section{RESULTS}

\section{Parental Behaviour}

In both food treatments, number of prey items brought per night by mothers and fathers were not significantly correlated with mean nestling age (Pearson correlations, all four $P>0.59$ ). This indicates that when we recorded 
begging behaviour, mothers already started to feed their brood at a constant level, mothers providing on average $33 \%$ of all prey items (Table 1). Three results are consistent with the hypothesis that nestlings cannot anticipate which parent will arrive next to the nest. First, mean absolute arrival time at the nestbox did not differ between male and female partners both when offspring were food-satiated (2447 hours; paired $t$ test: $t_{22}=0.35$, $P=0.73)$ and food-deprived (2439 hours; $t_{19}=0.30$, $P=0.77)$. Second, mean arrival time at the nestbox with food in two successive nights was not repeatable within individuals $\left(r \pm \mathrm{SE}=0.19 \pm 0.10 ; F_{50,47}=1.43, P=0.11\right)$ indicating that each parent does not show a fixed mean feeding time. Third, within nests the order of arrival of mothers and fathers did not deviate significantly from a random pattern (overall test: $\chi_{60}^{2}=40.9, P=0.97$ ). Only two of the 30 nights yielded a significant runs test, but in opposite direction: one night when father and mother alternated at the nest, and the other night with all mother visits first and all father visits second.

Mothers did not adjust feeding rate to the food supplementation experiment more finely than fathers. When offspring were food-satiated, fathers brought on average $5.8 \pm 4.0$ prey items per night and mothers $2.9 \pm 3.1$, and when offspring were food-deprived, $7.4 \pm 5.8$ and $3.1 \pm$ 2.5 , respectively (mixed model ANOVA with square-root transformed feeding rates, nest site as random variable: $F_{26,78}=0.72, P=0.83$; sex of parents: $F_{1,78}=22.26, P<$ 0.0001; food treatment: $F_{1,78}=1.16, P=0.29$; interaction sex by food treatment: $F_{1,78}=0.04, P=0.84$ ). Fathers and mothers brought each prey species to a similar frequency (chi-square test on prey species with more than five individuals: $\chi_{4}^{2}=6.36, P=0.17$; Table 1 ). Interestingly, fathers appeared to adjust feeding rate to brood size more finely than females at least when chicks were food-deprived (repeated measures ANCOVA with father and mother feeding rates as repeats, brood size: $F_{1,25}=7.43, P=0.012$, interaction sex by brood size: $F_{1,25}=4.51, P=0.04$; Fig. 1 ). In the food-satiated treatment, feeding rate was correlated with brood size in fathers $(r=0.43, N=27, P=0.025)$ but not in mothers $(r=0.32, N=27, P=0.10)$; however, the interaction between sex and brood size was not significant in a repeated measures ANOVA $(P=0.42)$. Altogether these results may indicate that males are more sensitive to brood begging rate, because mean number of begging calls produced in a nest was positively correlated with brood size (multiple regression analysis with mean number of begging calls as the dependent variable: brood size as first independent variable: $F_{1,24}=12.34, P=0.002$; amount of time parents stayed in the nest as second independent variable: $\left.F_{1,24}=46.86, P<0.0001\right)$.

In the two food treatments, fathers and mothers stayed a similar amount of time on the perch before entering their nestbox (median is $7.0 \mathrm{~s}$; mixed model ANCOVA in Table 2). This model showed that both parents stayed longer on the perch when nestlings were food-satiated than when they were food-deprived. In another mixed-model ANCOVA (Table 2), mothers stayed longer than fathers in their nestbox $(29.1 \pm 1.8 \mathrm{~s}$ vs. $15.4 \pm 1.2 \mathrm{~s})$ and both parents stayed longer when nestlings were food-satiated than when fooddeprived. This model also showed that parents stayed longer
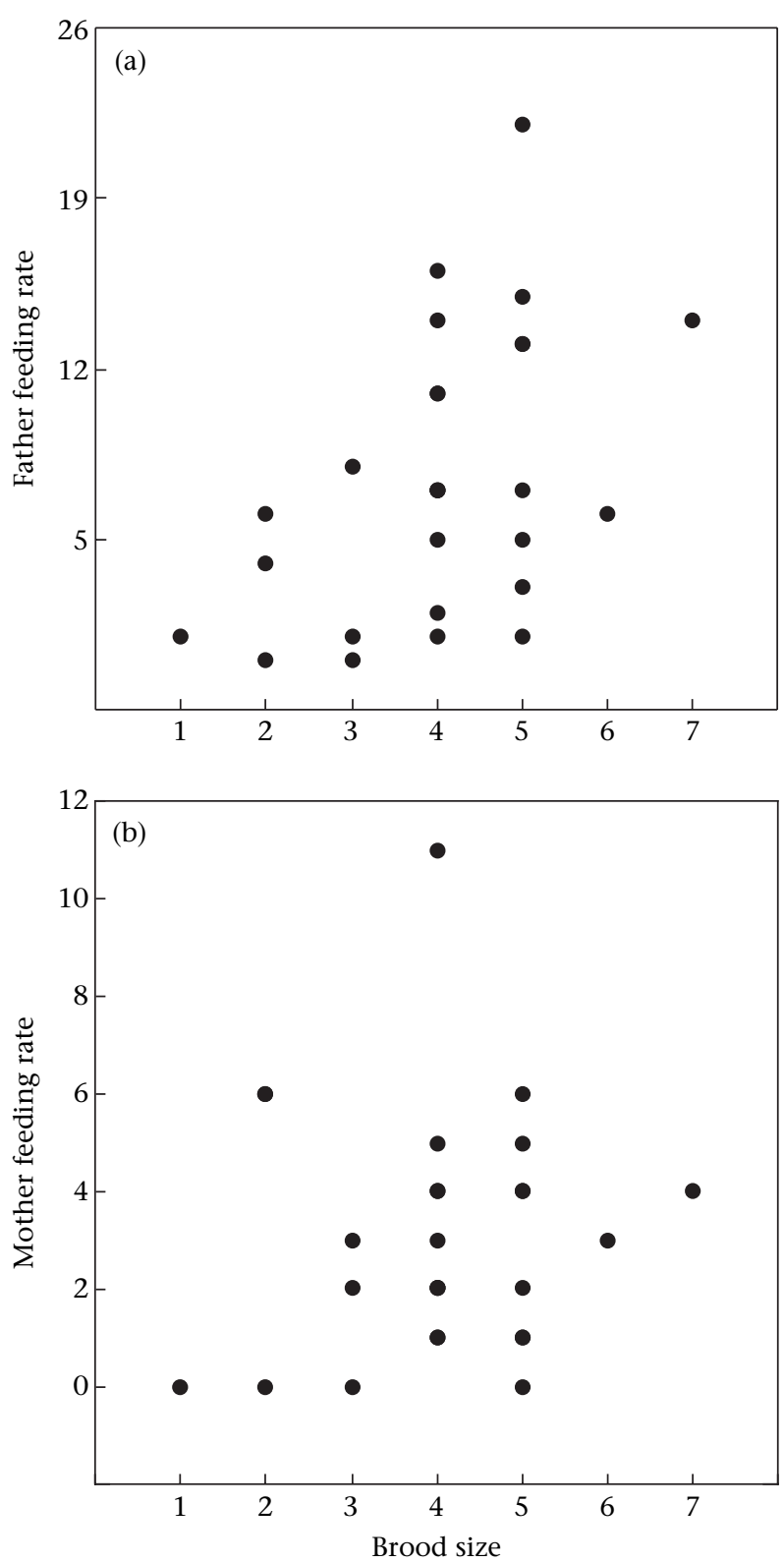

Figure 1. Relationship between feeding rate (number of prey items brought to the nest between 2130 hours and 0530 hours) and brood size when nestlings were food-deprived. (a) Father feeding rate and (b) mother feeding rate. Pearson correlation between feeding rate and brood size is significant in fathers $(r=0.47, N=27$, $P=0.013)$ but not in mothers $(r=0.11, N=27, P=0.60)$.

in their nestbox at the end than at the beginning of the night, an effect that was stronger in females than in males.

At the first feeding visit of the night in two-chick broods for which food supply was not manipulated, mothers transferred their prey item more rapidly than fathers (ANCOVA with amount of time as the dependent variable, sex: $F_{1,34}=6.61, P=0.015$, Fig. 2 ; mean nestling age as a covariate: $F_{1,34}=0.63, P=0.43$ ). This result is consistent with the finding that in food-manipulated broods for which the size was kept unchanged, mothers transferred their prey item to one offspring without entering the 
Table 2. Mixed model ANCOVAs testing whether mothers and fathers stay different amount of time on the perch and in nestboxes, whether siblings negotiate differently before the arrival of their mother than their father, and whether nestlings beg to different levels in the presence of their mother than in the presence of their father

\begin{tabular}{|c|c|c|c|c|c|c|c|c|c|c|c|c|}
\hline \multirow[b]{2}{*}{ Source } & \multicolumn{3}{|c|}{ Amount of time on perch } & \multicolumn{3}{|c|}{ Amount of time in nestbox } & \multicolumn{3}{|c|}{ Sibling negotiation } & \multicolumn{3}{|c|}{ Begging } \\
\hline & $F$ & $d f$ & $P$ & $F$ & $d f$ & $P$ & $F$ & $d f$ & $P$ & $F$ & $d f$ & $P$ \\
\hline \multicolumn{13}{|l|}{ Fixed effects } \\
\hline Sex of parents & 1.72 & 1,475 & 0.19 & 47.86 & 1,452 & $<0.0001$ & 0.93 & 1,569 & 0.33 & 8.03 & 1,440 & 0.0048 \\
\hline Food treatment & 15.93 & 1,475 & $<0.0001$ & 17.33 & 1,452 & $<0.0001$ & 74.47 & 1,569 & $<0.0001$ & 2.32 & 1,440 & 0.13 \\
\hline Arrival time & 1.10 & 1,475 & 0.29 & 33.48 & 1,452 & $<0.0001$ & 40.31 & 1,569 & $<0.0001$ & 4.67 & 1,440 & 0.03 \\
\hline Amount of time in nestbox & - & - & - & - & - & - & - & - & - & 863.66 & 1,440 & $<0.0001$ \\
\hline Sex*food treatment & 0.28 & 1,475 & 0.60 & 0.03 & 1,452 & 0.86 & 0.12 & 1,569 & 0.73 & 0.04 & 1,440 & 0.84 \\
\hline Sex*arrival time & 0.49 & 1,475 & 0.48 & 4.76 & 1,452 & 0.03 & 0.12 & 1,569 & 0.73 & 0.05 & 1,440 & 0.83 \\
\hline Sex*amount of time in nestbox & - & - & - & - & - & - & - & - & - & 18.3 & 1,440 & $<0.0001$ \\
\hline \multicolumn{13}{|l|}{ Random effects } \\
\hline Nest site & 13.93 & 22,475 & $<0.0001$ & 6.61 & 26,452 & $<0.0001$ & 2.74 & 26,569 & $<0.0001$ & 16.65 & 26,440 & $<0.0001$ \\
\hline
\end{tabular}

These dependent variables were log-transformed. Sex of parents and food treatment (i.e. food-deprived and food-satiated) were two factors, and absolute arrival time of parents at the nestbox (i.e. hour of the night) and log-transformed amount of time parents stayed in the nestbox were two covariates. Interactions are indicated by *. To control for pseudoreplication, we added the nest as a random factor in the model.
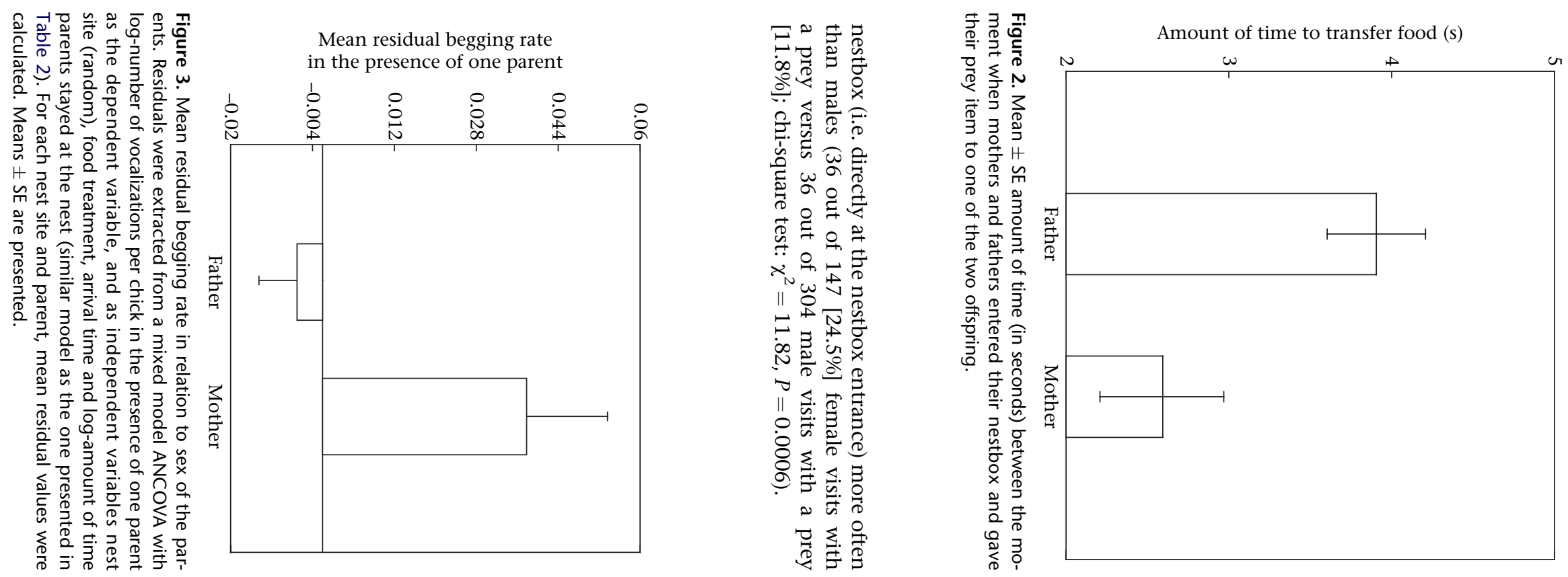


\section{Nestling Vocalization in the Absence and Presence of Mother and Father}

Nestlings were similarly hungry before their mother as before their father arrived at the nest with a prey item. This is shown by the fact that nestlings vocalized as intensely before the mother as before the father came to the nest (mixed model ANCOVA in Table 2). In this model, nestlings negotiated more intensely when food-deprived than when food-satiated, and at a lower level at the end compared with at the beginning of a night.

In a mixed model ANCOVA (Table 2), nestlings begged more intensely in the presence of the mother than in the presence of the father (Fig. 3) after controlling for nest site and log-amount of time parents stayed in their nestbox. Nestlings begged more intensely at the beginning than at the end of the night, whereas the food treatment had no significant effect on begging. The interaction between amount of time parents stayed in their nestbox and sex of parents was significant indicating that the increase in the number of begging calls with amount of time parents stayed in their nestbox was more pronounced in the presence of the mother than in the presence of the father.

\section{DISCUSSION}

Parent-offspring and sexual conflicts can select fathers to restrict feeding to different offspring from the same brood than mothers (Lessells 2002) and empirical studies in birds showed that males and females are often differentially sensitive to offspring begging (Kölliker et al. 1998; Krebs 2001; Quillfeldt et al. 2004; but see Price 1998; Whittingham et al. 2003). These facts suggest that offspring should beg differently towards their mother than towards their father because the probability of being fed may increase with begging intensity more steeply in one parent than in the other. Differential begging to mother and father implies that offspring should be able to recognize the identity of each parent.

In the present study, we found that nestling barn owls begged more intensely in the presence of their mother than in the presence of their father although they were similarly hungry, because sibling negotiation level was similar before the arrival of the mother as before the father. These results are in the same vein as those from a similar study in the great tit showing that nestlings compete more intensely for the nest position where the mother than the father predictably feeds them (Kölliker et al. 1998). In contrast to the great tit study that considered nestling physical behaviour including jostling for position, gaping and wing flapping, behaviours that are important in sibling competition, we measured begging vocalization, a trait that may have evolved as a signal directed to parents. This latter proposition is corroborated by the observation that begging rate, but not sibling negotiation, is associated with which chick is fed in priority by parents (sibling negotiation influences begging rate but not within-brood food allocation by parents; Roulin 2004b). This indicates that siblings compete (Kölliker et al. 1998) and signal food need (present study) to a larger extent in presence of their mother compared with in the presence of their father.

In the great tit, nestlings compete more intensely to monopolize maternal rather than paternal attention because mothers feed the hungriest offspring preferentially, whereas males are less selective with respect to offspring need in how they allocate food among the brood (Kölliker et al. 1998). Unfortunately, the exact reason why nestling barn owls begged more intensely towards the mother is still unclear. Although mothers stayed longer at the nest than males, they transferred their prey item to one of the offspring more rapidly than males. This observation suggests that either mothers are less sensitive than fathers to offspring begging to decide which offspring to feed in priority or, alternatively, mothers are highly sensitive to begging and rapidly assess which chick to feed first. Therefore, why did nestlings beg more intensely in the presence of their mother? A first possibility is that nestlings try to induce the mother to feed them with prey remains stored in the nestbox. This interpretation is unlikely because the interaction between sex of the parents and food treatment on nestling begging was not significant. Indeed, because there were more uneaten prey items throughout the night in food-supplemented than food-satiated broods, the offspring tendency to beg more intensely towards the mother should have been more pronounced when fooddeprived than when food-satiated, which was not the case. An alternative explanation is that females may be more prone to adjust feeding rate in relation to offspring begging. Again, the available data do not support this hypothesis because females did not adjust feeding rate more finely than males to the food supplementation experiment. Furthermore, if one of the two parents is more inclined to adjust feeding rate to begging rate, we rather expect males than females to do so. Indeed, brood size was positively associated with male but not with female feeding rate, and number of begging calls per minute produced by the entire brood increased with brood size.

Given that nestlings were observed to beg more intensely towards their mother than towards their father, it may have been adaptive for siblings to negotiate differently before the arrival of their mother than that of their father, because previous negotiation influences the way nestlings beg and in turn within-brood food allocation (Johnstone \& Roulin 2003; Roulin 2004b). The finding that sibling negotiation was not associated with sex of the incoming parent suggests that nestlings are unable to anticipate which parent will be the next feeder. In support to this proposition, mothers and fathers brought food at a similar mean time, and furthermore they did not show any consistent pattern of arrival time.

\section{Acknowledgments}

The Swiss National Science Foundation supported this work (grand $\mathrm{n}^{\circ}$ PP00A-102913). The 'Service vétérinaire du canton de Vaud' gave us authorisation (no. 1146) to manipulate food supply. The comments provided by Arnaud Baylon, Pierre Bize, Yannick Chittaro, Philippe 
Christe and two anonymous referees were helpful to improve a first draft of the manuscript.

\section{References}

Baudvin, H. 1986. La reproduction de la chouette effraie (Tyto alba). Le Jean le Blanc, 25, 1-125.

Bühler, P. \& Epple, W. 1980. Die Lautäusserungen der Schleiereule (Tyto alba). Journal für Ornithologie, 121, 36-70.

Burford, J. E., Friedrich, T. J. \& Yasukawa, K. 1998. Response to playback of nestling begging in the red-winged blackbird, Agelaius phoeniceus. Animal Behaviour, 56, 555-561.

Durant, J. M. \& Handrich, Y. 1998. Growth and food requirement flexibility in captive nestlings of the European barn owl (Tyto alba). Journal of Zoology (London), 245, 137-145.

Durant, J. M., Gendner, J.-P. \& Handrich, Y. 2004. Should I brood or should I hunt: a female barn owl's dilemma. Canadian Journal of Zoology, 82, 1011-1016.

Godfray, H. C. J. 1995. Evolutionary theory of parent-offspring conflict. Nature, 376, 133-138.

Johnstone, R. A. \& Godfray, H. C. J. 2002. Models of begging as a signal of need. In: The Evolution of Begging, Competition, Cooperation and Communication (Ed. by J. Wright \& M. L. Leonard), pp. 1-20. Dordrecht: Kluwer Academic.

Johnstone, R. A. \& Roulin, A. 2003. Sibling negotiation. Behavioral Ecology, 14, 780-786.

Kölliker, M., Richner, H., Werner, I. \& Heeb, P. 1998. Begging signals and biparental care: nestling choice between parental feeding locations. Animal Behaviour, 55, 215-222.

Krebs, E. A. 2001. Begging and food distribution in crimson rosella (Platycercus elegans) broods: why don't hungry chicks beg more? Behavioral Ecology and Sociobiology, 50, 20-30.

Leonard, M. L. \& Horn, A. G. 2001. Begging calls and parental feeding decisions in tree swallows (Tachycineata bicolor). Behavioral Ecology and Sociobiology, 49, 170-175.

Lessells, C. M. 2002. Parentally biased favouritism: why should parents specialize in caring for different offspring? Philosophical Transaction of the Royal Society of London, Series B, 357, 381-403.

McRae, S., Weatherland, P. J. \& Montgomerie, R. 1993. American robin nestlings compete by jockeying for position. Behavioral Ecology and Sociobiology, 33, 101-106.

Mikkola, H. 1983. Owls in Europe. Calton: T. \& A. D. Poyser.

Mock, D. W. \& Parker, G. A. 1997. The Evolution of Sibling Rivalry. Oxford: Oxford University Press.

Mondloch, C. J. 1995. Chicks hunger and begging affect parental allocation of feeding in pigeons. Animal Behaviour, 49, 601-613.
Newton, I. 1979. Population Ecology of Raptors. Calton: T. \& A. D. Poyser.

Ottosson, U., Bäckman, J. \& Smith, H. G. 1997. Begging affects parental effort in the pied flycatcher Ficedula hypoleuca. Behavioral Ecology and Sociobiology, 41, 381-384.

Parker, G. A. 1985. Models of parent-offspring conflict. V. Effects of the behaviour of the two parents. Animal Behaviour, 33, 519-533.

Parker, G. A. \& Macnair, M. R. 1979. Models of parent-offspring conflict. IV. Suppression: evolutionary retaliation by the parent. Animal Behaviour, 27, 1210-1235.

Price, K. 1998. Benefits of begging for yellow-headed blackbird nestlings. Animal Behaviour, 56, 571-577.

Quillfeldt, P., Masello, J. F. \& Hamer, K. C. 2004. Sex differences in provisioning rules and honest signalling of need in Manx shearwaters, Puffinus puffinus. Animal Behaviour, 68, 613-620.

Roulin, A. 1998. Importance de la nichée et croissange pondérale chez les jeunes chouettes effraies Tyto alba. Alauda, 66, 273-278.

Roulin, A. 2001. Food supply differentially affects sibling negotiation and competition in the barn owl (Tyto alba). Behavioral Ecology and Sociobiology, 49, 514-519.

Roulin, A. 2002. Barn owl. Update: Journal of the Birds of the Western Palearctic, 4, 115-138.

Roulin, A. 2004a. The function of food stores in bird nests: observations and experiments in the barn owl Tyto alba. Ardea, 92, 69-78.

Roulin, A. 2004b. Effect of hatching asynchrony on sibling negotiation, begging, jostling for position and within-brood food allocation in the barn owl, Tyto alba. Evolutionary Ecology Research, 6, 1083-1098.

Roulin, A., Kölliker, M. \& Richner, H. 2000. Barn owl (Tyto alba) siblings vocally negotiate resources. Proceedings of the Royal Society of London, Series B, 267, 459-463.

Slagsvold, T. 1997. Brood division in birds in relation to offspring size: sibling rivalry and parental control. Animal Behaviour, 54, 1357-1368.

Sokal, R. R. \& Rolff, F. J. 1995. Biometry. New York: W. H. Freeman.

Stamps, J. A., Metcalf, R. A. \& Krishnan, V. V. 1978. A genetic analysis of parent-offspring conflict. Behavioral Ecology and Sociobiology, 3, 369-392.

Tolonen, P. \& Korpimäki, E. 1996. Do kestrels adjust their parental effort to current or future benefit in a temporally varying environment? Ecoscience, 3, 165-172.

Trivers, R. L. 1974. Parent-offspring conflict. American Zoologist, 14, 249-264.

Whittingham, L. A., Dunn, P. O. \& Clotfelter, E. D. 2003. Parental allocation of food to nestling tree swallows: the influence of nestling behaviour, sex and paternity. Animal Behaviour, 65, 1203-1210. 